\title{
A ÉTICA COMO CONATUS DE ESPINOSA
}

Ana Pedro*

\begin{abstract}
Resumo: Neste artigo, procuraremos analisar o papel e a importância do conatus na economia do pensamento espinosiano, bem como a novidade que, a este propósito, o mesmo encerra para o entendimento de uma ética imanente do sujeito. Compreendido como o esforço despendido pelo sujeito no sentido de perseverar no seu ser, o qual, enquanto individualidade, procura o que é bom e útil para si, o conatus, tal como Espinosa o entende, é, no entanto, um princípio dinâmico que não pode reduzir-se à mera "conservação" do ser, mas é capaz de fazer mover o sujeito na escolha de afeções positivas que o realizem. É, sobretudo, na Parte II da Ética - da origem e da natureza das afeções -objeto de análise do presente artigo, que estas ideias se encontram desenvolvidas, em que o conhecimento (razão) é o afeto quando transformado na causa adequada de si mesmo.
\end{abstract}

Palavras-chave: afeções; liberdade; conhecimento; ética; conatus

"A felicidade não é o prémio da virtude, mas a própria virtude; e não gozamos dela por refrear as paixões, mas, ao contrário, gozamos dela por podermos refrear as paixões".

(Espinosa, Etica. IV, prop. XXXV, p. 389)

Espinosa (1632-1677), filósofo racional, cuja obra fundamental - Ética (1677) constitui a síntese do seu pensamento ontológico, epistemológico, antropológico e ético, surge com um carácter profundamente inovador e revolucionário face à sua época Renascimento - em que, apesar de se assistir ao emergir de uma nova sensibilidade científica e filosófica, ainda era profundamente marcada por um espírito de religiosidade fortemente acentuado, do qual o próprio Espinosa foi alvo e que esteve na origem da publicação póstuma da Ética (1677).

Com efeito, Espinosa não construiu o seu sistema filosófico em resposta à religiosidade cristã, tentando provar a existência de Deus, como era prática entre os filósofos da época, preferindo erigir, antes, um pensamento que tivesse em consideração a realidade humana:

Rompendo com os preconceitos e com a crença de que o sujeito é senhor das suas determinações, Espinosa substitui na Ética a postura moralista pela de cientista natural. Os afetos ganham status, pois não são de modo algum neutros, afinal, o desejo, a alegria, a tristeza, o amor, o ódio e todos os afetos que colorem nossa existência, possuem causas determinantes e efeitos necessários dignos de conhecimento. (Filho 8, p. 48).

\footnotetext{
* Professora Doutora da Universidade de Aveiro - Dep. Educação. Investigadora do MLAGFLUP- Universidade do Porto - Portugal.
} 
É, nesse sentido, que a sua obra Ética (1677) aparece como uma proposta de libertação do sujeito e das suas afeções negativas, as paixões, sempre através da razão, assente no pressuposto fundamental de que quanto maior for o conhecimento que o sujeito detiver dos mecanismos afetivos aos quais está sujeito, maior será a sua capacidade de intervenção neles e de se poder libertar das afeções negativas, substituindo-as por outras maiores e mais positivas.

Não se tratava, portanto, de provar a dependência do humano face ao divino, mas de acordar a capacidade do humano face à sua própria transformação com vista ao alcançar da liberdade máxima, o bem supremo.

Este novo tipo de ética, de que Espinosa é o autor, não principia por estabelecer primados exteriores ao sujeito para que este os possa vir a atingir, adequando a sua realidade àqueles, mas, ao invés disso, parte precisamente da realidade humana no que ela tem de negativo, sem o refutar - as afeções negativas - para transformá-las em afeções positivas (Silva 18; Amorim \& Gacki 2; Arruda 3).

Em todo este processo, o conatus vai desempenhar um papel absolutamente primordial, pois é duplamente entendido, não só como um esforço de perseverança no ser ou de preservação do ser num determinado estado, mas também como impulso, energia vital de transformação do ser em direção à sua maior perfeição.

Analisar a importância que o conatus tem na ética de Espinosa, isto é, qual o papel que o desejo, ou os afetos, desempenham no seu pensamento filosófico moral implica, antes de mais, saber o que o autor entende por ética e moral - o que são o Bem e o Mal? -; qual o seu carácter - imanente ou transcendente? -; qual a lógica que lhe está subjacente - lógica binária, maniqueísta ou circular e relacional? -; qual a sua relação com o conhecimento - que tipo de conhecimento pode estar implicado na afetividade? E, qual o seu objetivo - em que medida terá a razão um papel primordial em conduzir os afetos à sua libertação máxima para atingir o bem supremo?

É, sobretudo, na Parte II da Ética - da origem e da natureza das afeções -, objeto de análise do presente artigo, que Espinosa se dedica particularmente ao estudo dos afetos e apresenta a sua definição como sendo "toda a coisa se esforça, enquanto está em si, por perseverar no seu ser” (Espinosa 7, Parte III, Proposição VI, p. 275), ou ainda, "o esforço pelo qual toda a coisa tende a perseverar no seu ser não é senão a essência actual dessa coisa" (Espinosa 7, Parte II, Proposição VII, p. 276).

Mas, em que consiste o carácter dessa perseveração no ser? 
Uma coisa ou algo que procura persistir no seu estado pretende continuar a assumir a forma da sua existência, ou seja, não morrer.

Assim sendo, "o conatus é $[\ldots]$ o impulso vital pelo qual todo o ser tende a afirmar-se enquanto ser; é expressão de vida, presente em tudo o que implique vida; uma constituição inerente, integrante de cada indivíduo tendente, naturalmente, a afirmar a sua existência" (Aquino 1, p. 181).

Por outro lado, este esforço do conatus para permanecer existente, também pode ser interpretado como sendo "aquele que se esforça para se expandir, que busca aprimoramento, perfeição, um constante esforço para aumentar a sua potência" (Amorim \& Gacki 2, p.11).

Isto é, o conatus, cuja origem etimológica significa esforço (positivo), diferentemente entendido de apetite ou pulsão (ex: fome, sede), é o desejo que constitui a realidade humana, que faz parte dela e que não é passível, sequer, de ser negada.

Deste modo, Espinosa, muito claramente parte do pressuposto de que a realidade humana é um todo não divisível, em que a alma não existe separada do corpo (Filho 7; Silvia 18).

Em seu entender, o ser humano tanto é egoísta como altruísta, bom como perverso, generoso como calculista. O homem representa cada um destes estados antagónicos, pelo que é, simultaneamente, razão e emoção.

O entendimento da realidade humana, segundo Espinosa, não passa, por isso, por uma lógica binária que separe a razão da paixão, ou por um pressuposto moral meramente maniqueísta que dissocie o bem do mal, ou ainda, que estabeleça o princípio dicotómico de desunião entre o corpo e a mente, pois aceita os seres humanos como eles se apresentam, como um todo, cujas partes interatuam (Arruda 3; Fragoso 10).

Assim sendo, se o bem e o mal não existem enquanto conceitos absolutos, postulados exteriormente ao sujeito, mas como realidades experienciadas e vividas por cada um, então, bem e mal correspondem a experiências, ou modos de existir subjetivos, que traduzem diferentes níveis, ou graus, de experienciação.

É, neste sentido, que muito frequentemente afirmamos que "não desejamos as coisas porque as consideramos boas: ao contrário, nós as consideramos boas porque as desejamos" (Mariotti 13, p. 11).

É de notar, contudo, que este facto introduz certo relativismo que se adequa à esfera da individualidade de cada sujeito, algo completamente alheio à prática do seu tempo, na medida em que aquilo que é considerado bom para um sujeito, pode não ser 
considerado da mesma maneira para outro, remetendo-nos, assim, para a esfera da subjetividade.

Deste modo, como definir o que é o bom e o que é o mau? Como esclarecer o sentido de cada um deles e estabelecer os seus limites diferenciadores?

É interessante verificar que, a este nível, há uma semelhança quanto à forma como a ética é entendida entre Espinosa e Nietzsche (Cardoso 5), pois, se para Espinosa, o bom e o mau existem por determinação livre e subjetiva do sujeito que os escolhe, no sentido de agir na preservação da essência do seu ser, para Nietzsche, o mesmo tipo de questionamento é colocado como necessidade de ultrapassar a tirania arbitrária de uma qualquer moral que nos é totalmente extrínseca.

O conatus, tal como Espinosa o entende, é, portanto, um princípio dinâmico que não pode reduzir-se à mera "conservação" do ser, e, enquanto o ser se esforça por perseverar no seu ser, ou por manter a sua essência, a sua individualidade ${ }^{1}$, o homem é, nesse sentido, igual a todos os outros seres existentes na natureza, dado que tal atitude ou predisposição lhes é verdadeiramente inerente ao seu modo de ser.

Contudo, esse esforço (conatus) é, ao mesmo tempo, especial no homem, uma vez que somente ele pode ter consciência da realização desse esforço enquanto tal (autoconsciência). Mas, adianta interessantemente Espinosa, esse facto não dota o homem de um privilégio ontológico superior face aos demais seres, muito embora o distinga deles.

O desejo é, assim, o que leva o sujeito a perseverar no seu ser, enquanto individualidade, e a procurar o que é bom e útil para si; ou seja, nessa tarefa de procura de si, o sujeito não é remetido para a busca de algo transcendente ${ }^{2}$, mas do que possa ser imanente a ele próprio, ou seja, de tudo aquilo quanto possa vir a potenciar a sua natureza. Ajustado à sua natureza, o bom não pode, por isso, ser transcendente ao sujeito, mas imanente.

Para Espinosa, o conatus é a essência (EIII, P7) do ser humano, enquanto consciência dos apetites e traduz "o esforço pelo qual cada coisa tende a perseverar no seu ser não envolve tempo finito, mas um tempo indefinido" (Parte II, Proposição VIII, p. 276); é, em última análise, o que nos impele a procurar as afeções positivas, como a alegria, por exemplo.

O desejo (conatus) entendido, então, como força positiva que nos leva a expandir a nossa potência na direção da obtenção da excelência, apreendida como 
felicidade, encaminha-nos na procura do que é bom e útil para nós e no evitar de tudo o que é mau, encarando este último como um obstáculo à realização do ser (Amorim \& Gacki 2; Sévérac 17).

Porém, se as afeções não são apenas positivas, mas igualmente negativas, sendo estas as mais problemáticas, importa saber de que modo pode o sujeito escolher as primeiras e evitar as segundas.

E, mesmo sendo o conatus um esforço positivo, o que é que o determina nesse sentido? Por outras palavras, como controlar as paixões, como evitar o seu poder e força exacerbadas? Como procurar sempre aquilo que nos é útil, ou bom, que aumente a nossa potencialidade de ser ou realização da essência? Como pode o homem agir positivamente sem se sentir externamente compelido a tal?

Para Espinosa, a resposta contém dois sentidos que dizem respeito quer à liberdade (autodeterminismo), a qual, por sua vez, está intrinsecamente associada ao conhecimento, pois este amplia a nossa potência para agir positivamente; quer à razão (conhecimento), na medida em que é esta que ajuda o homem a pensar adequadamente em relação às paixões.

Razão e liberdade adquirem, pois, um papel primordial no trajeto, ou no percurso estabelecido pelo sujeito para alcançar com sucesso, o seu fim último, que é a libertação ou o atingir do bem supremo, que é a felicidade.

Deste modo, Espinosa não renega as paixões que caracterizam a existência humana para alcançar a felicidade; muito pelo contrário, parte delas, mas para ultrapassá-las, ajudando o homem a libertar-se, através do exercício da razão como forma de realização da essência do humano, como já referimos.

A este propósito, é de assinalar a existência de certa similitude entre Aristóteles e Espinosa, na medida em que ambos concedem um lugar primordial à capacidade do sujeito escolher ser, sempre mediante a razão, quer quando a phronesis aristotélica, enquanto virtude, não aponta explicitamente para um fim previamente determinado, interessando-lhe mais a natureza do processo virtuoso em si, do que propriamente o seu resultado, o qual deverá ser construído à imagem e à medida de cada sujeito, quer quando, em Espinosa, todas as escolhas livres que o sujeito fizer serão sempre aquelas que respeitam a essência do seu ser.

Com efeito, para Espinosa, conhecimento implica liberdade e liberdade implica conhecimento: quanto mais conhecimento eu tiver das minhas afeções (sentimentos, emoções), mais liberdade terei no meu agir em função da realização do meu ser; i.é, 
mais atos autodeterminados eu serei capaz de realizar, em vez de estes serem determinados por causas exteriores (Gomes 11; Fragoso 9; Castro 6).

Liberdade $^{3}$, para Espinosa, é, pois, sinónimo de autodeterminação, ou de livre determinação interior, não exterior, segundo a qual o sujeito decide sem ser motivado por uma obrigação ou por um constrangimento, mas é levado a agir somente determinado por si mesmo, ainda que tal possa ser ilusório e enganador aos olhos do homem: contudo, não significa que não se possa escolher.

O conhecimento, por sua vez, ocupa, igualmente, um lugar de destaque no pensamento espinosano, a par do da liberdade, pelo que, desta feita, importa saber, qual o tipo de conhecimento implicado na afetividade; ou seja, "que potência o conhecimento nos dá para lutarmos contra os maus afetos?” (Sévérac 17, p. 31).

Conhecimento e afetividade estão intrinsecamente interligados em Espinosa (Silva 18; Bittencourt 4; Paula 15; Loos 12), na medida em que o conhecimento mais profundo sobre a natureza da afetividade humana visa a sua transformação, ou libertação, para atingir a felicidade suprema.

Deste modo, ao conhecimento está associada uma finalidade ética que tem por objetivo fundamental fortificar a mente, no sentido de dar razões a esta para agir em função da realização do seu ser.

Porém, o que pode mesmo o mais puro conhecimento racional perante a força devastadora dos afetos?

O que se passa é que, frequentemente, o conhecimento que temos do futuro face a situações acráticas ${ }^{4}$, por exemplo, é de natureza abstrata e contingente, pelo que não adquire um carácter premente e obrigatório para o sujeito, mas facultativo, enquanto que o conhecimento que temos do presente é concreto e necessário.

Por outro lado, os desejos que nascem da imaginação que acompanham o conhecimento do futuro são menos potentes que os desejos que acompanham o conhecimento do presente, pelo que, muito embora saibamos que comer chocolate, por exemplo, ou fumar, faça mal à saúde, acabamos, na maioria das vezes, por incorrer nessas ações, cedendo, assim, à "tentação" (acrasia).

No entender de Espinosa, para evitar tais circunstâncias, trata-se de encarar a possibilidade de agir, desde logo, no momento presente e, deste modo, prevenir futuras situações de maior "tentação"; i.é, sabendo que o sujeito se irá certamente defrontar no futuro com estados acráticos, este poderá, através da imaginação racional, começar a ensaiar racionalmente um conjunto de respostas possíveis, entre tantos outros cenários 
desejáveis, que lhe permitam resistir aos piores afetos passionais e desejar os bons, atingindo o seu objetivo final que é manter a perseveração no ser.

Assim sendo, a razão é, simultaneamente, impotente face às afeções passionais do presente, mas potentíssima face a situações idênticas, ou piores, de prevenção no futuro, enquanto fonte racional de afetividade, capaz de resistir às piores afeções: "o conhecimento racional serve-se, portanto, do conhecimento imaginativo para moderar, destruir, ou até transformar do interior dos afetos passionais" (Sévérac 17, p. 36; Paula 15; Pinheiro 16).

Conclui-se, assim, que a racionalidade em Espinosa não é concebida de uma forma dissociada da ética de ser, na medida em que a nossa conduta só será boa, ou virtuosa, se fundada na razão, no conhecimento, aliás, tal como Aristóteles também defendia.

Todavia, nada disto se efetivará se não tiver o conatus como base motora essencial capaz de fazer mover o sujeito na escolha de afeções positivas que o realizem. Assim, a triangulação entre conatus, liberdade e conhecimento traduz, em nosso entender, a possibilidade de atingir o bem supremo (felicidade): o conhecimento puro, por si só, não é capaz de mover para a (melhor) ação; a liberdade, por sua vez, necessita do conhecimento para poder escolher, decidir; o conatus, informado por estes dois elementos, é aquele que consegue mover à ação racionalmente deliberada e escolhida, o único possuidor de uma força capaz de, simultaneamente, se auto-preservar e expandir, no sentido do aprimoramento, da perfeição e da excelência do ser. Contudo, faz tudo isto numa tentativa de permanecer na sua existência (princípio de autoconservação e de aprimoramento).

$\mathrm{Ou}$ seja, o conatus permite que nos tornemos a causa adequada das nossas próprias ações (autodeterminação), que sejamos ativos, dinâmicos (dinamismo do ser), alegres (Paula 14) e livres (ética da liberdade).

\section{Considerações finais}

Espinosa apresenta uma nova ética ontológica que parte do entendimento do Homem enquanto modo finito de ser constituído por corpo $e$ mente, ideias e pensamentos que afetam e são afetados pelas coisas e pelos corpos.

Esta postura opõe-se à da filosofia tradicional que assinalava a existência de uma separação entre conhecimento e razão, por um lado, e afeto e paixões, por outro lado, 
sendo aqueles aspetos essenciais caracterizadores do homem, e os afetos, uma imagem da sua animalidade.

Com efeito, Espinosa não renega a realidade dos afetos e das paixões e parte efetivamente delas para se elevar na busca do que é bom e útil para si, não no sentido transcendente, mas de algo que possa ser imanente a si mesmo, ou seja, de tudo aquilo quanto possa vir a potenciar a sua natureza.

Neste sentido, o conatus é, em última análise, o que nos impele a procurar as afeções positivas, como a alegria, por exemplo; é ainda, aquilo que nos leva a expandir a nossa potência na direção da obtenção da excelência.

Neste processo, razão e liberdade adquirem um papel primordial em que o sujeito visa alcançar com sucesso, o seu fim último, que é a libertação ou o atingir do bem verdadeiro, que é a felicidade.

\section{The Ethics as Spinoza's conatus}

Abstract: In this article, we will analyze the role and importance of the conatus in the economy of Spinoza's thought, as well as the innovation that, in this respect, the same holds for the understanding of a subject's immanent ethics. Understood as the effort spent by the subject in order to persevere in his own being, which, while individuality, searches for what is good and useful for himself, the Spinoza's conatus, as he understood it, is, however, a dynamic principle that cannot be reduced to mere "conservation" of being, but is able to move the subject in choosing positive affections that accomplish himself. It is, above all, in part II of the Ethics -the origin and nature of affections -object of analysis of this article, that these ideas are developed, in which the knowledge (reason) is the affection when transformed into the appropriate cause of itself.

Keywords: affections; knowledge; ethics; Spinoza's conatus; liberty

\section{REFERÊNCIAS BIBLIOGRÁFICAS}

1. AQUINO, J. Considerações acerca do problema moral em Espinosa e Nietzsche. Pp. 179-190. Disponível em:

http://www.benedictusdespinoza.pro.br/Artigo_Jefferson_Aquino_Spinoza_Nietzsche.p df

2. AMORIN, W. \& GACKI, S. Desejo e beatitude em Spinoza. Revista Húmus. №2. Pp. 514. (2011).

3. ARRUDA, I. As noções de corpo e mente de Benedictus de Spinoza. Revista Conatus. 
Filosofia de Spinoza. Vol. 5. No10. Dez. Pp. 45-56. (2011).

4.BITTENCOURT, R. Para uma compreensão da política dos afetos na filosofia de Espinosa. Revista Filosofia Capital. Vol. 3. No 7. Pp. 83-100. (2008).

5.CARDOSO, H. Espinosa e Nietzsche: elos onto-práticos para uma ética da imanência. Anais do I Seminário de Filosofia Contemporânea. Nietzsche e o pensamento francês. Londrina-PR: IEL. Vol.1.Pp. 23-33. (2006).

6.CASTRO, F. (2006). Substância, Liberdade e existência. Impasses metafísicos em Spinoza. Revista Eletrónica Internacional.

Disponível em:

http://www.senspublic.org/IMG/pdf/SensPublic_FCaprio_Substancia_Liberdade_e Exi stencia.pdf. 7.ESPINOSA, B. (1992). Ética. Lisboa: Relógio d'Água.

8.FILHO, F. (2010). Afecções: uma releitura a partir de António Damásio, das emoções em Espinosa. Curitiba: Universidade Federal do Paraná.

9. FRAGOSO, E. O conceito de liberdade na ética de Benedictus de Spinoza. Revista Conatus. Filosofia de Spinoza. Vol.1.№1. Pp. 27-36. (2007).

10. FRAGOSO, E. Considerações sobre a definição VII da parte I da Ética de Benedictus de Spinoza. Kalagatos. Revista de Filosofia da UECE. Fortaleza. Vol. 1. No 1. Pp. 107-128. 2004.

11.GOMES, D. O problema do conceito de liberdade na ética de Spinoza. Revista do Seminário dos Alunos do PPGLM/UFRJ. Nº1. (2010).

Disponível em: http://seminarioppglm.files.wordpress.com/2009/04/gomes-d-oproblema-do-conceito-de-liberdade-na-etica-de-espinosa1.pdf.

12.LOOS, H. \& Sant'Ana, R. Cognição, afeto e desenvolvimento humano: a emoção de viver e a razão de existir. Educar. Curitiba. No 30. Pp. 165-182. (2007).

13. MARIOTTI, H. O Conhecimento do conhecimento: a filosofia de Espinosa e o pensamento complexo. Disponível em: http://www.geocities.com/pluriversu.

14. PAULA, M. (2009). Alegria e felicidade. A experiência do processo libertador em Espinosa. São Paulo: Universidade de São Paulo.

15.PAULA, M. Saber, ação e afeto: o problema da acrasia em Aristóteles e Espinosa. Cadernos Espinosa. Estudos sobre o século XVII. N. XVI Jan-Jun. São Paulo. Pp. 6188. (2007).

16.PINHEIRO, U. Servidão e acrasia segundo Espinosa. O que nos faz pensar No⒙ setembro. Pp. 195-212. (2004). 
17.SÉVÉRAC, P. 2009. O conhecimento como o mais potente dos afetos. Pp.17-58.

Disponível em:

http://www.martinsfontespaulista.com.br/anexos/produtos/capitulos/591740.pdf.

18.SILVA, A. Conhecimento e afetividade em Espinosa. Revista Eletrônica de Educação e Ciência (REEC). Vol. 2. N 3. Pp. 33-45. (2012).

19.SILVIA, C. (2007). Corpo e pensamento: alianças conceituais entre Deleuze e Espinosa. Campinas: São Paulo.

\section{NOTAS}

${ }^{1}$ Em Espinosa, a dimensão de indivíduo é aquilo que faz com que um indivíduo seja um indivíduo (individualidade), e está associado à atividade da sua perseverança no seu ser (autopreservação), a qual corresponde, em última análise, num esforço em ser livre.

2 A este propósito, Amorin \& Gacki (2, p 9), estabelecem uma diferenciação entre os conceitos de transcendência, compreendida no sentido platónico, de algo que existe para além da realidade sensível; e transcendental, referente àquela qualidade que pode ser afirmada de qualquer coisa e que existe em relação de independência quanto à sua origem. O conceito de imanência opõe-se, assim, ao de transcendência, na medida em que se refere à existência de tudo quanto há no mundo, e identifica-se com o de transcendental, uma vez que os atributos de algo co-participam em graus diferentes entre si, conceito este mais próximo do entendimento de imanência de Espinosa, de acordo com o qual, tudo se dá na imanência do mundo, não existindo transitividade, ou separação, entre as coisas, formando uma substância única, de que o ser é exemplo. Quando aplicado a Deus, este conceito não significa absoluta indeterminação nem está associado a entendimento (sabedoria) ou mesmo vontade (livre arbítrio), mas antes a necessidade livre, pois Deus, que é Natureza, produz necessariamente todas as coisas e existe pela necessidade da sua natureza (Fragoso 9).

${ }^{3}$ Quando aplicado a Deus, este conceito não significa absoluta indeterminação nem está associado a entendimento (sabedoria) ou mesmo vontade (livre arbítrio), mas antes a necessidade livre, pois Deus, que é Natureza, produz necessariamente todas as coisas e existe pela necessidade da sua natureza (Fragoso 9).

${ }^{4}$ A acrasia é entendida como a ação, tomada pelo agente, de agir de modo contrário aos seus melhores juízos iniciais; trata-se de uma ação intencional, mas irracional, pois o sujeito parece agir contra aquilo que ele próprio havia inicialmente deliberado como sendo o melhor. Na Apologia de Sócrates (25e), vemos ser defendida a ideia de que ninguém é mau voluntariamente, tal como no Protágoras, entre outros diálogos platónicos, onde Sócrates nega a existência de acrasia, na medida em que parte do pressuposto de que é impossível que os agentes não atuem em conformidade com o que consideram saber ser o melhor. Contudo, a ascensão ao logos só é permitida a alguns, apenas aos melhores: aqueles que agem mal não o fazem por maldade, mas sim por erro ou desconhecimento. Na continuidade deste pensamento, a acrasia é, então, inexistente e a ação errada é provocada apenas pela ignorância. Na esteira de Aristóteles, para quem, contrariamente a Sócrates, a acrasia era considerada inexistente, reduzindo-a a 
uma questão de (des)conhecimento, esta é mais como um problema moral de conflito entre dois ou mais desejos, tratando-se, portanto, mais de uma questão de auto controlo, ou falta dele, do que propriamente um problema de conhecimento. 